\title{
In-vitro seed germination Trial for the population Terminalia ivorensis Collected from Benchi-Maji zone, south western Ethiopia
}

Mohammed Adefa ( $\nabla$ mohammed.adefa.seid@gmail.com )

Ethiopian Environment and Forest Research Institute

Yigardu Mengesha

Ethiopian Environment and Forest Research Institute

Semaigzer Ayalew

JEFRC, Ethiopian Environment and Forest Research Institute

Marshet Nigatu

JEFRC, JEFRC, Ethiopian Environment and Forest Research Institute

Wondu Kebede

JEFRC, JEFRC, Ethiopian Environment and Forest Research Institute

Research Article

Keywords: Terminalia, germination, treatments, temperature

Posted Date: November 1st, 2021

DOI: https://doi.org/10.21203/rs.3.rs-1016021/v1

License: (c) (1) This work is licensed under a Creative Commons Attribution 4.0 International License.

Read Full License 


\title{
In-vitro seed germination Trial for the population Terminalia ivorensis Collected from Benchi-Maji zone, south western Ethiopia
}

\author{
Mohammed Adefa ${ }^{1}$, Yigardu Mulatu ${ }^{2}$, Semaigzer Ayalew ${ }^{3}$, Marshet Nigatu ${ }^{3}$, Wondu Kebede $^{3}$ \\ ${ }^{1}$ Central Ethiopia Environment and Forest Research Center, EEFRI, ${ }^{2}$ Ethiopian Environment and \\ Forest Research Institute (EEFRI), ${ }^{3}$ Jimma Environment and Forest Research Center, EEFRI \\ ${ }^{1}$ Corresponding author's email: mohammed.adefa.seid@gmail.com
}

\begin{abstract}
Tree seeds exhibit some degree of dormancy. Similarly, the seeds of Terminalia ivorensis germinate with great difficulties. To break the dormancy and improve the germination capability of seeds, different types of mechanical and physiological approaches can be followed. Accordingly, the seeds of $T$. ivorensis were subjected to two pre-sowing treatments (one is with seeds soaked in water for 24 hours and the other is with seeds soaked for 10 minutes in $80 \%$ concentrated $\mathrm{H}_{2} \mathrm{SO}_{4}$ then abundantly rinsed in running water for 20 minutes) in addition to the control one. So, a total of 100 seeds divided into 4 replications ( 25 seeds per tray) were tested for each treatment. Then, treated seeds were sown in sand tray to seed the germination characteristic of the different treatments. The sown seeds were followed up for 5 months with proper watering, and the germination record was taken accordingly. Analysis of the germination of the different treatments shows that seeds that were not treated exhibits better mean germination percentages (62\%) followed by the one with seeds soaked for 24 hours (47\%). However, seeds treated with $80 \%\left[\mathrm{H}_{2} \mathrm{SO}_{4}\right]$ for 10 minutes then abundantly rinsed in running water for 20 minutes showed no germination. So, both the $62 \%$ and $47 \%$ germination recorded are fairly accepted results considering the low germination capacity of $T$. ivorensis in laboratory and natural conditions. However, other possible pre-sowing treatment techniques can be studied and incorporated for increasing the seed germination of $T$. ivorensis in-vitro in addition to the records obtained in this trial.
\end{abstract}

Key words: Terminalia, germination, treatments, temperature 


\section{Introduction}

Tree seeds always exhibit some degree of dormancy resulting a delay and irregularity of germination seeds in the nursery and even in forest floors (Maiden et al., 1990; Oyewole and Adedamola, 2015). Hence, in order to obtain better germination condition and quantity of seedlings, it is always necessary to apply pre-sowing treatment techniques. The number of seedlings produced from a given number of seeds is termed as germination percentage (germination rate) which is the direct measurement of viability of a given seed lot (Guerke, 2005). Terminalia ivorensis are among the most important of the some 200 species belonging to the genus Terminalia (Combretaceae). Terminalia ivorensis trees are bisexual or hermaphroditic (male and female gametophytes found on the same flowers). The stalked male flowers tend to be grouped towards the apex and the bisexual flowers towards the base of the inflorescences (Coates-Palgrave, 1977; Oyewole and Adedamola, 2015). Although male and female flowers are in the same plant, self-pollination do not always produce viable zygotes (Newbegin et. al., 1994). Insects such as Coleoptera, Diptera, Hemiptera, Hymenoptera and Lepidoptera are the common vector pollinators of Terminalia (Uzoechina, 1978). The floweringto-fruiting period may last for about 4 months, depending on the locality where it is grown (Coates-Palgrave, 1977).

In most cases, the seeds of Terminalia ivorensis germinate with great difficulties. This inability to germinate is caused by the seed coat; most probably because this is thick and lignified. To improve the germination potential of seeds of $T$. ivorensis, applying different pre-sowing treatment (both mechanical and physiological) of seeds is necessary. In our case, Seeds of Terminalia ivorensis collected from west Ethiopia are tested to determine their germination status with and without pre-sowing treatments. Therefore, the objective of this trial was to determine the germination characteristics of Terminalia ivorensis seeds using different presowing techniques. 


\section{Material and Methods}

Material preparation: Seeds were collected from Benchi-Maji area of southwest Ethiopia. After procurement, the cones were exposed to sun heat for $24 \mathrm{~h}$ and then the seeds were collected after natural opening. Seeds extracted were further purified to $97 \%$ and the moisture content was maintained to $<5 \%$. The number of seed $/ \mathrm{kg}$ was found to be 12155 . Hence, the seed sample was subjected to three different pre-sowing treatment methods 1) control-untreated, 2) seed soaked in water for 24 hours, and 3) seeds soaked for 10 minutes in $80 \%$ concentrated $\mathrm{H}_{2} \mathrm{SO}_{4}$ then abundantly rinsed in running water for 20 minutes.

The seeds of $T$. ivorensis have a size of greater than $2 \mathrm{~mm}$. So, germination trial on sand tray is most recommended as to ISTA. So, a total of 300 pre-treated seed (100 seeds for each treatment divided into 4 replications in which 25 seeds were sown per a tray). Then, proper watering and follow up was done for six months (June-October, 2020). Therefore, data for germinated seeds ( $\geq 1 \mathrm{~mm}$ radicals) recorded for a period of 5 months after sowing.

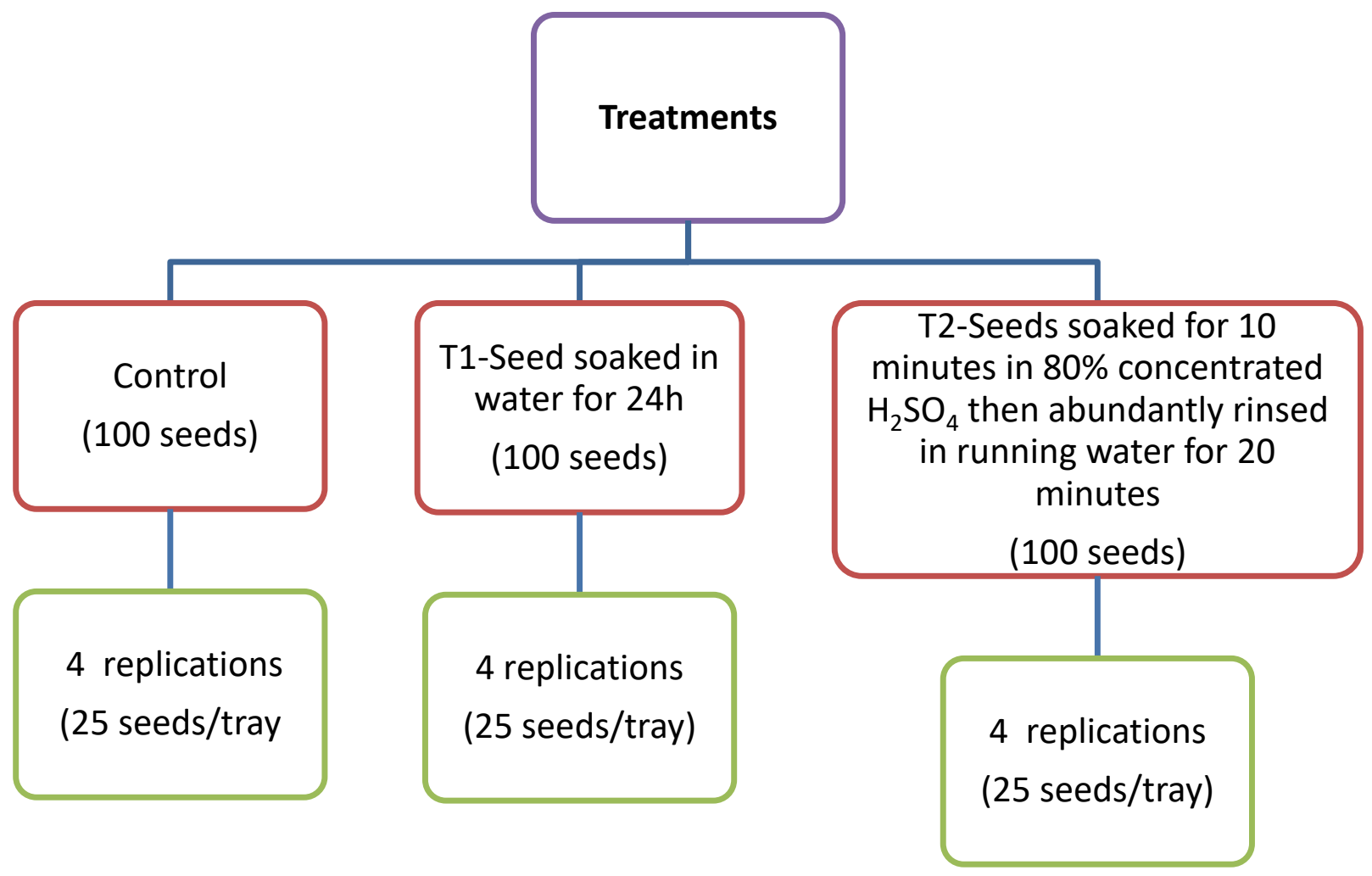

Figure 1. Illustration of the sampling procedures of the seeds of $T$. ivorensis before sowing 
The average percentage germination of each treatment was calculated using the formula:

$$
\% \text { germination }=\frac{\text { Number of seeds germinated }}{\text { Total number of seeds swwn }} \times 100
$$

\section{Results and Discussions}

Analysis of the germination records shows that seeds that were not treated (i.e. control) show better germination compared to the seeds that were treated. Accordingly, the mean germination percentage of untreated seed is found to $62 \%$ followed by seeds soaked for 24 hours (47\%). However, seeds treated with $80 \%\left[\mathrm{H}_{2} \mathrm{SO}_{4}\right]$ for 10 minutes then abundantly rinsed in running water for 20 minutes showed no germination. So, both the $62 \%$ and $47 \%$ germination recorded are fairly accepted ones considering the low germination capacity of $T$. ivorensis in laboratory conditions. However, other possible pre-sowing treatment techniques can be studied and incorporated for increasing the seed germination of $T$. ivorensis in-vitro in addition to the records obtained in this trial. As, the result, it is observed that application of $\mathrm{H}_{2} \mathrm{SO}_{4}$ is not an option. However, other possible pre-sowing treatments can be reviewed and tested in addition to these tested treatments techniques. On the other hand, seed germination trial for T. ivorensis by lbe et al (2015) using three growing media (sawdust, sterilized river sand and garden topsoil) show that the highest germination percentage $(9.44 \%)$ was recorded on the topsoil growing media. 


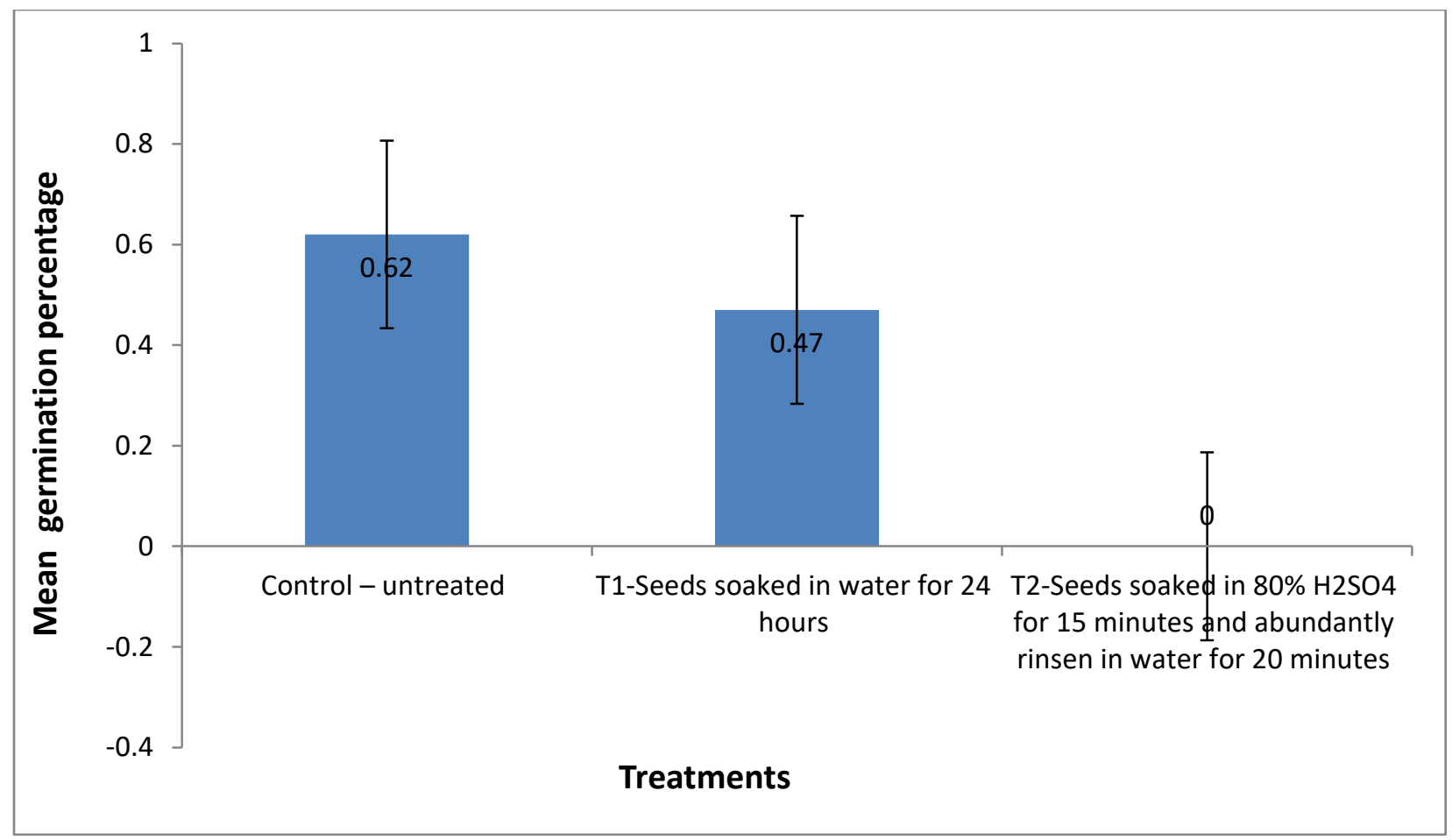

Figure 3. Mean germination percentages of the different treatments in sand substrate after six months observation

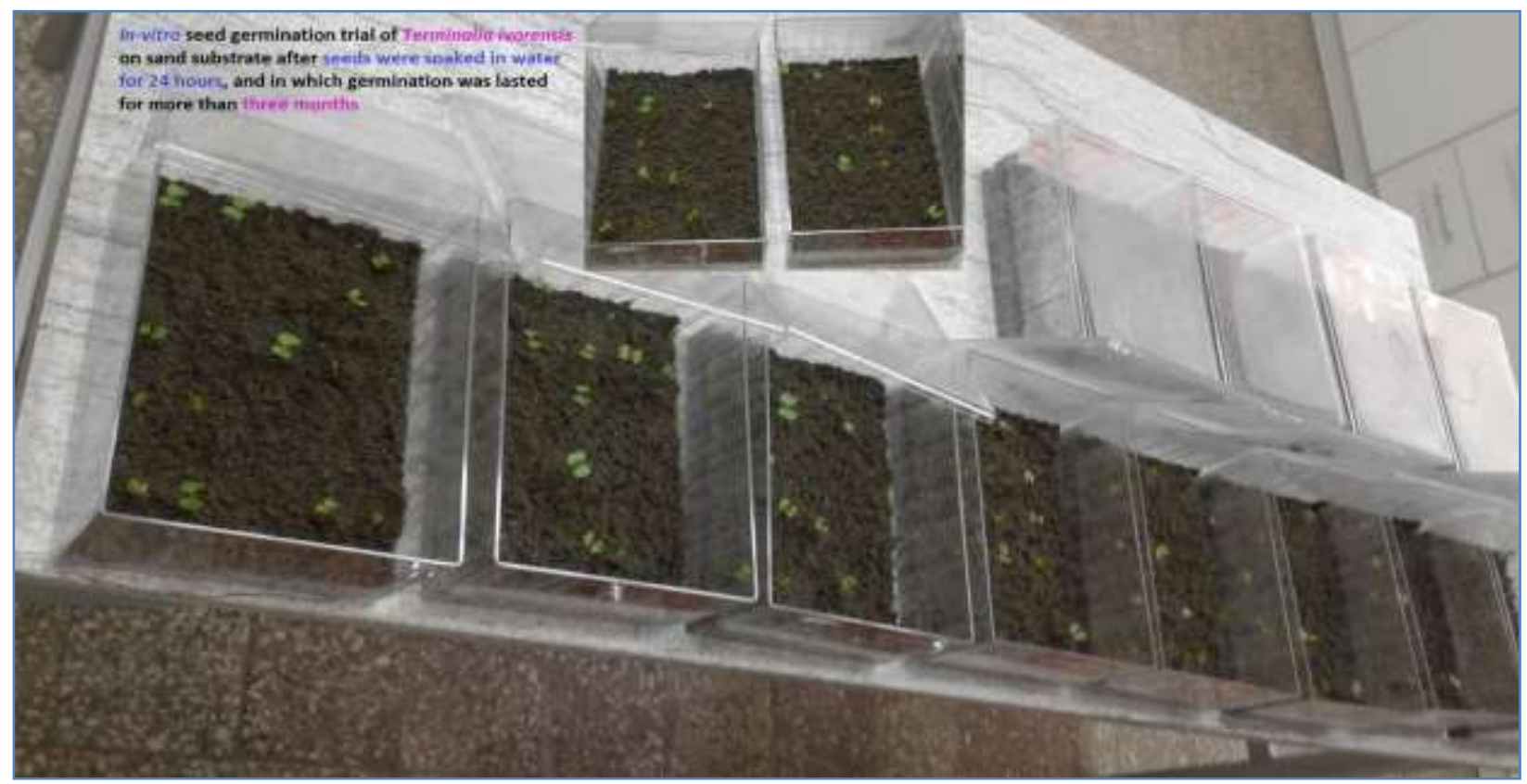

Figure 3. In-vitro seed germination trail of $T$. ivorensis on sand substrate 


\section{Conclusion}

Terminalia ivorensis is among the most important tree species. The seeds of $T$. ivorensis germinate with great difficulty which is most probably caused by the thick and lignified seed coat. So, in order to improve the germination of seeds and obtain better quantity and quality of seedlings to support the conservation and plantation works, it is necessary to manipulate the seed structure and physiology of seeds so as to break the seed dormancy and instigate the germination capability. In this study, in addition to the control group, the seeds of $T$. ivorensis collected from Benchi-Maji zone were subjected to different pre-sowing treatments (seed soaked in water for 24 hours, and seeds soaked for 10 minutes in $80 \%\left[\mathrm{H}_{2} \mathrm{SO}_{4}\right]$ then abundantly rinsed in running water for 20 minutes). A total of 100 seeds were tested using sand tray method for each treatment. In this study, the germination of the different treatments shows that the untreated seeds give rise better germination percentages (62\%) followed by the one with seeds soaked for 24 hours (47\%). However, seeds treated with $80 \%\left[\mathrm{H}_{2} \mathrm{SO}_{4}\right]$ showed no germination. Overall, both the $62 \%$ and $47 \%$ germination recorded are fairly accepted results considering the low germination capacity of $T$. ivorensis in laboratory and natural conditions. However, it is recommended for further studies and experimentation incorporating additional pre-sowing treatments such as nicking and hormonal treatments in order to improve germination rates. Moreover, experimentation using seed tissue culture is also the way forward for achieving better seeds germination capabilities. 


\section{Acknowledgement}

UNDP-EFCCC is well acknowledged for financially supporting this project work. We are also grateful to the local communities and government sector offices in the study areas for making this work possible.

\section{References}

- Coates-Palgrave, O.H. (1977). Trees of Central Africa. National Publications trust Rhodesia and Nyasaland, Cape Town.

- Guerke, W.R. (2005). Evaluating peanut seed vigour. Seed Technology, 27(1): 121-126.

- Ibe, A.E., Adeyemi, A.A., Nwuda, B.N., Asiabaka, C.C. and Onuoha, G.N. (2015). Seed Germination and Seedling Growth of Terminalia ivorensis (A. Chev) in Different Growth Media. FUTO Journal Series (FUTOJNLS), 1(2), 138-145.

- Maiden, S.K., Jacqueline, A.S. and Vinaya Rai, R.S. (1990). Presowing chemical treatment to hasten germination of Casuarinas equisetifolia. International Tree Crop. Journal, 6. 173-181.

- Newbigin, E., Anderson, M.A., Clarke, A.E. (1994). Gametophic self-incompatibility in Nicotiana alata, in: Williams EG, Clarke AE, Knox RB (Eds). Genetic Control of Self-incompatibility and reproductive Development in Flowering Plants. Kluver Academic Publishers, Dordrecht, Holland. Pp. 5-18.

- Oyewole1, A.L. and Adedamola, A. (2015). nfluence of Temperature Differentials on Germination and Growth of Terminalia ivorensis (A. Chev). Science Research, 3(6): 296-299. Doi: 10.11648/j.sr.20150306.15. 